\title{
O Programa de Educação Integral no Ensino Médio Regular em Pernambuco e suas utilizações
}

\section{The Integral Education in Regular High Scholl Program in Pernambuco and its uses}

\section{El Programa de Educación Integral en Escuela Secundaria en Pernambuco y sus usos}

\author{
Jamerson Antonio de Almeida da Silva ${ }^{1}$ \\ Katharine Ninive Pinto Silva ${ }^{1}$
}

DOI: http://dx.doi.org/10.20435/serie-estudos.v24i51.1135

\begin{abstract}
Resumo: $O$ artigo tem como tema o ensino médio integral e integrado e, como objetivo, analisar as utilizações do Programa de Educação Integral no Ensino Médio regular em Pernambuco, considerando as promessas de formação de jovens. Para tanto, foi realizada pesquisa de avaliação da implementação de política pública, através de análise documental e bibliográfica, além de diálogo com outras pesquisas realizadas sobre o mesmo tema e objeto de estudo. Os resultados indicam que a Rede Estadual de Ensino de Pernambuco utiliza o Programa de Educação Integral no ensino médio para promover uma organização do trabalho pedagógico neoprodutivista, através de ênfase na gestão gerencial, com grande perda para os docentes envolvidos no processo, tanto do ponto de vista da organização coletiva, quanto em relação às questões de ordem individual. Tais utilizações repercutem também nas escolas que não adotam o Programa, pois fazem parte do sistema construído sobretudo para abrigar aqueles que não serão considerados adequados ao modelo adotado pelo Programa.
\end{abstract}

Palavras-chave: Ensino Médio; educação integral; utilizações.

\begin{abstract}
The article has the theme of integrated and integrated secondary education and aims to analyze the uses of the Program of Integral Education in regular high school in Pernambuco, considering the promises of training of young people. For that, a research was carried out evaluating the implementation of public policy, through documentary and bibliographic analysis and a dialogue with other researches carried out on the same theme and object of study. The results indicate that the State Education Network of Pernambuco uses the Integral Education Program in high school to promote an organization of neoprodutivist pedagogical work, through an emphasis on managerial management, with great loss for the teachers involved in the process, both from the point of view of View of collective organization, as well as individual issues. Such uses also have repercussions in schools that do not adopt the Program, since they are part of the system built mainly to house those that will not be considered adequate to the model adopted by the Program.
\end{abstract}

1 Universidade Federal de Pernambuco, Recife, Pernambuco, Brasil. 
Keywords: High School; integral education; uses.

Resumen: El artículo tiene como tema la enseñanza media integral e integrada y con objetivo analizar los usos del Programa de Educación Integral en la Enseñanza Media regular en Pernambuco, considerando las promesas de formación de jóvenes. Para ello, se realizó una investigación de evaluación de la implementación de política pública, a través de análisis documental y bibliográfico además de diálogo con otras investigaciones realizadas sobre el mismo tema y objeto de estudio. Los resultados indican que la Red Estadual de Enseñanza de Pernambuco utiliza el Programa de Educación Integral en la enseñanza media para promover una organización del trabajo pedagógico neoproductivista, a través de énfasis en la gestión gerencial, con gran pérdida para los docentes involucrados en el proceso, tanto del punto de de la organización colectiva, en cuanto a las cuestiones de orden individual. Tales usos repercuten también en las escuelas que no adopta el Programa, pues forman parte del sistema construido sobre todo para albergar a aquellos que no serán considerados adecuados al modelo adoptado por el Programa.

Palabras clave: Enseñanza Media; educación integral; usos.

\section{INTRODUÇÃO}

Este artigo trata de resultados parciais de pesquisa financiada através de edital de Ciências Humanas, Sociais e Sociais Aplicadas que tem como problema central: Como estão sendo implementadas as políticas de Educação Integral para jovens em Pernambuco, a partir das novas orientações/induções do governo brasileiro para o Ensino Médio regular e na modalidade EJA? Neste artigo, objetivamos analisar as utilizações do Programa de Educação Integral no Ensino Médio regular em Pernambuco, considerando as promessas de formação de jovens.

Segundo Algebaile (2009), a investigação da produção sobre a escola como instituição especializada requer o reconhecimento de que ela é constituída por elementos que não são necessariamente orientados para a função de educar, implicando explorar os seus sentidos mais profundos e o caráter histórico de suas especializações. A educação escolar como campo privilegiado da formação de sujeitos, construída a partir das relações estabelecidas entre os seres humanos históricos, não é um lugar neutro, ao contrário é perpassada por uma série de pressupostos ideológicos, culturais, políticos e filosóficos. A escola não é apenas reprodutora das relações dominantes presentes na sociedade. Porém a intensidade com que essas relações chegam à escola depende da forma como os sujeitos partícipes dessa instituição se organizam. Depende também de sua trajetória histórica.

Considerando tais aspectos, entendemos a produção da escola através de suas utilizações. Tal conceito envolve o conceito de uso, assim como Lefebvre 
(2006) trata, como estando relacionado à ideia de "apropriação", na qual estão incluídos "o afetivo, o imaginário, o sonho, o corpo, o prazer", que se relacionam aos valores de uso, implicando modos de ser e inserindo-se nos costumes. Assim carregam a possibilidade de insurreição, possibilitando, portanto, movimentos de resistência. E é, portanto, no vivido, como nível da prática imediatamente dada, que a natureza, ou seja, sua gênese, sua utilidade primeira, aparece e transparece como corpo, como "Uso". E consideramos o conceito de utilizações assim como Algebaile (2009, p. 148), buscando tratar do seguinte fenômeno:

[...] das múltiplas e persistentes tentativas de utilização, concreta ou simbólica, da escola; utilizações que repercutem em sua constituição, tornando-a, sob certos aspectos, mais robusta, ainda que isso represente sua fragilização em certos aspectos que deveriam ser essenciais".

Através de análise documental e bibliográfica, além de diálogo com outras pesquisas realizadas sobre o mesmo tema e objeto de estudo, organizamos a nossa abordagem teórico-metodológica no sentido de avaliar o Programa de Educação Integral (PEI) em implementação no Ensino Médio da Rede Estadual de Pernambuco. Para tanto, consideramos a contribuição de Castro (1989), no sentido de que uma política não deve ser avaliada apenas pelo valor de seu sucesso, mas também pela potencialidade de sucesso de sua implementação.

\section{PROGRAMA DE EDUCAÇÃO INTEGRAL DO ESTADO DE PERNAMBUCO E SUAS UTILIZAÇÕES}

Considerando o particular que estamos analisando, ou seja, as utilizações do Programa de Educação Integral (PEI) da Rede Estadual de Pernambuco, é preciso considerarmos em que consiste esse Programa. De acordo com Silva e Silva (2016), o PEl, que vem sendo desenvolvido desde 2008 pela Rede Estadual de Pernambuco, conjuga em sua proposta a implementação no ensino médio do tempo integral (ou semi-integral) ${ }^{2}$, da concepção de educação interdimensional ${ }^{3} \mathrm{e}$

\footnotetext{
${ }^{2}$ Por tempo integral, a Rede Estadual estipula 45 horas semanais, distribuídas em 5 dias da semana e, por tempo semi-integral, 32 horas semanais, distribuídas em 5 manhãs e 3 tardes, ou 5 tardes e 3 manhãs).

${ }^{3}$ A partir da compreensão de Costa (2008), que, por sua vez, seguiu as determinações da UNESCO, especialmente do Relatório Jacques Delors. Contempla ações direcionadas ao desenvolvimento das quatro dimensões do ser humano: logos (racionalidade), o pathos (afetividade), o eros (corporeidade) e o mytho (espiritualidade) (PERNAMBUCO, 2010). A proposta desse autor pressupõe a "criação de uma nova edu-
} 
da gestão da educacional e da escola a partir do gerencialismo ${ }^{4}$ e da contribuição dos empresários, com o estabelecimento de Parcerias Público-Privadas (PPPs) para esse fim. A gestão realizada na Rede Estadual de Pernambuco, assim descrita, foi implementada através do Programa de Modernização da Gestão Pública - Metas para Educação (PMGP-ME). De acordo com Silva e Silva (2016, p. 746),

O PMGP-ME foi criado em parceria com o Movimento Brasil Competitivo (MBC) e o Instituto de Desenvolvimento Gerencial (INDG), voltado para a melhoria dos indicadores educacionais do Estado. Por meio do Programa, são estipuladas metas verticalizadas para cada Escola, envolvendo a conjugação de três fatores: 1. uma avaliação própria do desempenho dos alunos em Língua Portuguesa e Matemática; 2. o Sistema de Avaliação da Educação de Pernambuco (SAEPE), que combinado com o fluxo escolar, define o resultado do Índice de Desenvolvimento da Educação de Pernambuco (IDEPE), ou seja, um índice próprio de qualidade e 3. o Bônus de Desempenho Educacional $(B D E)$, o chamado décimo quarto salario que é destinado apenas às escolas que atingiram a partir de $50 \%$ da meta estipulada pelo PMGP-ME. Articulada a esta estratégia de bonificação, existe também uma estratégia de sanção por meio da exposição pública dos resultados e do ranqueamento das escolas.

O PEI vem sendo implementado nas Escolas de Referência em Ensino Médio (EREMs) e nas Escolas Técnicas Estaduais (ETEs). No entanto muito mais do que o tempo integral e da proposta curricular na perspectiva da educação interdimensional, é a busca por melhores resultados da escola no IDEPE que define a organização do trabalho pedagógico nas escolas. De acordo com os resultados do IDEPE, são definidas as escolas e os profissionais que receberão um bônus, ou seja, um benefício salarial acrescido nos contracheques desses profissionais. Morais (2013) realizou entrevista com a Coordenadora Pedagógica do PEl à época, que consideraremos neste artigo. A entrevistada descreve o trabalho realizado no processo de monitoramento estabelecido pela gestão educacional, que faz parte dos procedimentos adotados pelo PMGP-ME:

É um monitoramento de resultados cognitivos, interdimensional e de auto avaliação do professor, essa realizada de acordo com cinco variáveis, como

cação, que seja capaz de reequilibrar as relações do logos, o mytho, e o eros de forma mais inteligente e harmônica" (COSTA, 2008, p. 20). Esse conceito baseia-se nos quatro pilares estruturadores do Relatório Jacques Delors: aprender a ser, aprender a conviver, aprender a fazer e aprender a aprender.

${ }^{4}$ Através da obrigação da área educacional em realizar planejamento estratégico aplicado às escolas, com a obrigação em elaborar um Plano de Ação Educacional a partir da Tecnologia Empresarial Odebrecht (TEO). 
eu me sai em relação: ao planejamento didático, a avaliação, a família e aos resultados. Esse monitoramento acontece bimestralmente e é feito por gestores e educadores de apoio que obtiveram os melhores resultados em sua região, esses ficam responsáveis por três escolas enquanto outros fazem a avaliação das suas escolas. O resultado é monitorado disciplina por disciplina, onde cada professor vai dizer o que acertou e o que errou e mostrar as causas do erro para assim poder buscar os responsáveis. De posse dos resultados se estabelece um plano de intervenção que também lança mão da auto-avaliação de cada professor. (Trecho de entrevista com a Coordenadora Pedagógica do PEI- MORAIS, 2013, p. 108-9).

A questão que norteia esse procedimento adotado na Rede Estadual de Pernambuco pode ser caracterizado aquilo que Apple (2015, p. 609) chama de "modernização conservadora": "a combinação entre o "novo" dos mercados, a accountability (aceitação de assumir a responsabilidade plena por decisões tomadas), e a eficiência junto com o "velho" da cultura e disciplina tradicionais". Para Apple (2015), a realização dessas tarefas voltadas para a accountability vem intensificando o trabalho na escola, com "[...] uma agenda interminável de reuniões e, em muitos casos, uma escassez crescente de recursos, tanto físico quanto emocionais" (APPLE, 2015, p. 623). A inclusão de tecnologia e a ênfase na gestão são características das mudanças que empresários fazem no nível da produção que é transferida para o campo da educação; essa forma de pensar a educação foi um achado de Saviani nos anos de 1980 a que chamou de Pedagogia Tecnicista. Hoje, essa mesma lógica se faz presente no campo educacional e, mais especificamente, na forma em que o PEI foi criado, baseado na ideia de uma gestão com visão gerencial, na premiação, nos resultados e na exposição pública destes. Podemos perceber que esse conjunto de pressupostos, como já tratamos anteriormente, se aproxima de como hoje esse tecnicismo se constitui.

Na Rede Estadual de Pernambuco, a pressão se dá especialmente em torno dos indicadores de qualidade baseados no mérito. Para Freitas (2012), a meritocracia é parte do sistema de responsabilização e prevê as recompensas e sanções como o não recebimento de gratificações, a partir dos resultados, até a própria exposição pública destes. Essa prática é observada em relação às EREMs, e seus resultados são amplamente divulgados na mídia pernambucana e até mesmo na mídia nacional.

Por outro lado, assim como sinaliza a coordenadora do PEI no trecho da entrevista já citado anteriormente, uma outra dimensão do Programa é a busca 
da formação interdimensional, nos moldes prescritos pela UNESCO e através do tratamento dado por Antonio Carlos Gomes da Costa (COSTA, 2008). Segundo a Coordenadora Pedagógica do PEI (MORAIS, 2013, p. 109), isso deve acontecer através da "pedagogia da Presença, que significa a presença educativa do professor, que dessa forma o levaria a perceber a identidade de cada estudante, conhecendo-o para poder se relacionar com este, estabelecendo uma relação de confiança". Morais (2013) considera que, de acordo com Costa (2008, p. 109), "esse conceito tem como base a influência positiva que o professor(a) deve ter com os estudantes, ou seja, uma influência construtiva, criativa e solidária a qual contribui de forma favorável no desenvolvimento pessoal e social dos estudantes". Também nas indicações do Instituto de Corresponsabilidade Educacional (ICE), parceiro do Governo anterior na construção das primeiras experiências de Educação Integral, afirmam a "presença educativa do professor, por meio da qual ele se responsabiliza pela educação integral dos jovens" (MAGALHÃES, 2008, p. 48). Conforme Silva e Silva (2016, p. 746-47):

O PEI foi criado a partir da mudança de forma da parceria público-privada realizada pelo Governo Eduardo Campos ao encerrar a parceria com o Instituto de Co-responsabilidade Educacional (ICE), que praticamente coordenou o Programa em voga anteriormente (desde 2004) - o PROCENTRO. No entanto, do ponto de vista de conteúdo, as parcerias público-privadas continuaram a existir neste novo Programa, assim como o modelo adotado de escolas de Ensino Médio de pequeno porte em condições de se tornarem Escolas por concessão, no modelo de Escolas Charters. Inclusive, um estudo encomendado à TREVISAN Consultoria, em 2007, concluiu que a opção por escolas de Ensino Médio, com mil alunos cada, espalhadas pelo Estado, como Centros Experimentais, daria conta de atender a metade da demanda de jovens com 160 escolas. A partir deste estudo, o PEI passou a envolver Escolas de Referência em Ensino Médio (EREMs) e Escolas Técnicas Estaduais (ETEs). Na atualidade, temos 300 (trezentas) EREMs e 27 (vinte e sete) ETEs.

A educação interdimensional baseia-se no conceito de competências, a partir dos Quatro Pilares da Educação, que são as aprendizagens que constituem o eixo estruturador para a Educação no século XXI do Relatório Jacques Delors: aprender a ser, aprender a conviver, aprender a fazer e aprender a conhecer. Conforme a Coordenadora pedagógica do PEI (MORAIS, 2013, p. 110):

Nessa escola além da avaliação cognitiva que a gente faz, a gente faz uma avaliação do desenvolvimento interdimensional do estudante onde cada 
professor avalia o estudante nas competências de Jaques Delors: aprender a ser, aprender a conviver, aprender a fazer e aprender a aprender, no final de cada bimestre, a gente tem isso agora já num sistema, "tabajara", mas é. Eles se reúnem num colegiado e cada um diz como é que estar o desenvolvimento do estudante em relação àquelas capacidades, que é o detalhamento das competências.

As quatro aprendizagens propostas pela UNESCO são traduzidas na proposta de Educação Interdimensional nas seguintes competências:

Competências pessoais são aquelas relacionadas ao encontro da pessoa consigo mesma, no processo de busca da realização do seu potencial, ou seja, das promessas que trouxe consigo ao vir a este mundo.

Competências relacionais são aquelas que possibilitam à pessoa relacionar-se com as outras pessoas, com o mundo envolvente (natural e social), com a dimensão transcendente da vida (crenças, valores, significados e sentidos).

Competências produtivas são aquelas constituídas pelo conjunto dos conhecimentos, das habilidades e das atitudes, que dão condições à pessoa de ingressar, permanecer e ascender no mundo do trabalho, através do exercício de uma ocupação, serviço ou profissão. (PERNAMBUCO, 2010, p. 17).

Apple (2015) chama atenção para o fato de que, no neoliberalismo, "o Estado tomou a iniciativa de nos manter no nível de competência necessária. O Estado vai fazer com que cada um faça um "empreendimento contínuo de nós mesmos" ...no que parece ser um processo de "governar sem governar" (APPLE, 2015, p. 618). Com base na meritocracia, essa perspectiva neoliberal não busca refletir a questão da desigualdade social que, segundo Freitas (2012, p. 383) é a "base da construção da desigualdade de resultados". O efeito dessas políticas neoliberais se reflete em danos à juventude, pois há um processo de afastamento dos melhores professores daqueles alunos que mais precisam, tendo em vista que os critérios utilizados para qualificar esses professores vão se dar através do desempenho dos alunos nas avaliações em larga escala. Além disso, esse tipo de projeto de formação da juventude, promove uma formação limitada ao básico cuja defesa é que, para acessar conhecimentos mais complexos, depende-se de saber o básico:

Um argumento muito conhecido no âmbito do sistema capitalista e que significa postergar para algum futuro não próximo a real formação da juventude, retirando dela elementos de análise crítica da realidade e substituindo-se 
por um "conhecimento básico", um corpo de habilidades básicas de vida, suficiente para atender aos interesses das corporações e limitado a algumas áreas de aprendizagem restritas (usualmente leitura, matemática e ciências). A consequência é o estreitamento curricular focado nas disciplinas testadas e o esquecimento das demais áreas de formação do jovem, em nome de uma promessa futura: domine o básico e, no futuro, você poderá avançar para outros patamares de formação. (FREITAS, 2012, p. 389-90).

De acordo com Morais (2013), a partir da referência em Maués (2009, p. 115):

Uma proposta curricular assentada na ideia das competências, apesar de aparecer nos discursos como avanço, permite um estreitamento não apenas curricular, já que busca incessantemente a objetividade na busca por resultados, mas também uma limitação na formação da juventude. Pois, preso a um fazer lógico, permite a dominação por meio do conhecimento, na chamada economia do saber.

No processo de elaboração da proposta curricular do PEl, segundo a Coordenadora Pedagógica do Programa (MORAIS, 2003, p. 116), prevaleceu uma proposta conteudista, construída pelos professores da Rede Estadual de Ensino:

Em 2008 foram reunidos 880 (oitocentos e oitenta) professores com os formadores que foram selecionados entre aqueles de melhores resultados. Esse grupo de professores-formadores a cada ano aumenta em número. Inicialmente foram orientados a acessarem todos os instrumentos normativos sobre o currículo, bem como todas as propostas de vestibular e a partir desse conjunto de elementos consolidaram uma proposta. Depois desse momento os professores foram reunidos por região e de acordo com as seguintes áreas: Ciências, Natureza e Matemática; Linguagem, Código e Ciências Humanas. Nesses grupos discutiam as propostas e tiraram um consolidado de cada região. Os formadores reuniram as propostas de todas as regiões e assim foi construída a primeira proposta curricular [...].

Mas essa proposta, segundo a coordenadora, não estava adequada à perspectiva de educação interdimensional (com base no desenvolvimento de competências e habilidades), pois "os professores não estavam preparados para isso". Portanto, em 2010, a proposta foi reformulada, segundo a entrevistada, de acordo com a perspectiva de educação interdimensional:

[...] um processo difícil devido à deficiência na formação do professor que não contempla o trabalho a partir desses matizes além de ser uma propos- 
ta ainda com muitas competências e habilidades já representa um avanço em relação à proposta anterior. A maior dificuldade efetivamente estar na avaliação, ou seja, como avaliar a partir das competências e habilidades (Trecho de entrevista com a Coordenadora Pedagógica do PEI - MORAIS, 2013, p. 116).

De acordo com Freitas (2014), assistimos atualmente a uma disputa pela organização do trabalho pedagógico das escolas, que se funda em "teorias pedagógicas requentadas", em sua maioria tradicionais e com um tempero tecnicista.

\section{A ORGANIZAÇÃO DO TRABALHO PEDAGÓGICO DAS ESCOLAS DE REFERÊNCIA EM ENSINO MÉDIO}

De acordo com Morais (2013, p. 118), "os professores que atuam nas EREMs e nas ETEs são escolhidos através de uma seleção interna na própria rede estadual de ensino". Silva e Silva (2016) descrevem que os docentes optam por essas escolas sobretudo porque eles, ao atuarem no ensino médio em tempo integral (ou semi-integral), recebem "uma gratificação que chega a dobrar o salário base dos mesmos, em troca de Dedicação Exclusiva e uma jornada de 32 ou 40 horas semanais" (SILVA; SILVA, 2016, p. 13). De acordo com Morais (2013, p. 118):

A amarra objetiva é a gratificação, o tempo, as tarefas assumidas que vão definindo o perfil desse profissional, além do que a gratificação é uma forma de utilização política para controle político dos professores, impedindo que estes se organizem e desenvolvam uma identidade de classe capaz de resistir às mais diversas formas de controle.

Morais (2013, p. 119) identificou, em seu estudo, uma forma de utilização existente através do $\mathrm{PEI}$, em relação ao trabalho docente:

Essa utilização tem a ver com o controle político dos profissionais dessas escolas. Pois se por um lado há uma valorização financeira, por outro eles são impedidos de se organizarem coletivamente, como disse a coordenadora pedagógica em entrevista: "nossos professores não fazem greve, vão para formação dia de sábado, o que causou sérios problemas com o sindicato". Nesse sentido, não é apenas uma questão de valorização financeira, mas um controle da própria subjetividade do professor/a.

Além disso, Morais (2013, p. 119) também identifica estratégias em torno de garantir que os profissionais não tenham condições de faltarem ao trabalho em 
função de adoecimento, gravidez, estudo e participação em atividades de greve, sob pena de perderem o vínculo com o Programa e serem remanejados para uma escola de tempo parcial, perdendo também a gratificação. Compreendemos que a reflexão de Alves (2007, p. 247), de que "a preocupação fundamental do toyotismo é com o controle do elemento subjetivo no processo de produção capitalista", é fundamental para entendermos esse processo. O texto de Magalhães (2008) chega a afirmar que este modelo vai servir para quebrar a organização trabalhista dos professores:

É notoriamente conhecido o corporativismo na área de educação no Brasil. Os sindicatos alimentam e fazem uso político disso. Um observador atento pode verificar que, nas últimas décadas, os acordos sindicais da categoria foram essencialmente centrados em dois temas: trabalhar menos e ganhar mais. Esses acordos e as brechas legais levaram a uma situação no mínimo, vergonhosa: em São Paulo, um professor pode legalmente estar ausente da escola por cerca de 100 dias letivos! E, ainda falam que são mal remunerados. Urge, pois, que os sindicatos se elevem a outro patamar, como atores deste processo e se unam ao movimento de melhoria da educação de uma maneira suprapartidária. Só assim entenderão que é por meio da melhoria do resultado da aprendizagem que os professores criarão condições de ser, ainda, melhor remunerados. (MAGALHÃES, 2008, p. 7).

Esse modelo é baseado em experiências antigas desenvolvidas nos Estados Unidos e denunciadas por Ravitch (2011), como a desenvolvida em San Diego (1998-2005), cujas ações para "melhoria da qualidade da educação" envolviam gestão centralizada, ataque ao sindicato, demissão de gestores e professores e ênfase no treinamento e estreitamento curricular; como a desenvolvida na cidade de Nova York (2001-2009), que envolvia organização da administração das escolas, luta contra o sindicato dos professores, grandes aumentos salariais para professores e gestores (o que fazia com que a liderança do sindicato fosse grata ao prefeito, apesar de $80 \%$ dos sindicalizados desaprovarem a política educacional), fragmentação de grandes escolas de ensino médio em escolas menores, prática frequente de testes estaduais e fechamento das escolas com baixa performance.

Ainda para Magalhães (2008), o professor é tanto vítima quanto vilão no processo de ensino/aprendizagem, sendo a vilania creditada à vinculação destes aos interesses dos sindicatos:

Eu os classifico simultaneamente como vítimas e vilões. Vítimas da degradação da profissão (a classe média a abandonou), de uma infraestrutura escolar precária, da ausência de sistemas de reconhecimento e incentivo, 
de formação desvinculada da realidade escolar, das ingerências políticas no sistema. E vilões porque fazem o jogo dos sindicatos, entregam muito pouco resultado do seu trabalho à sociedade e ainda se consideram injustiçados [...] Nos meus vários anos de convivência com o setor da educação pública, deparei-me com inúmeros profissionais dedicados, apóstolos da causa e que não mediam esforços para, apesar das circunstâncias, transmitem o máximo de seus conhecimentos aos alunos. (MAGALHÃES, 2008, p. 7).

Nos Estados Unidos, de acordo com Ravitch (2011), como efeitos das políticas implementadas nas últimas décadas, "a estratégia produziu medo e obediência entre os educadores; ela muitas vezes gerava escores de testes mais elevados. Mas não tinha nada que ver com educação" (RAVITCH, 2011, p. 32). Na experiência norte-americana, a estratégia estava mais direcionada para sanções do que recompensas. De acordo com a autora, o mais inacreditável dessa perspectiva é que "Os slogans por muito tempo defendidos por políticos bitolados de direita migraram e agora foram adotados pelos políticos bitolados de esquerda" (RAVITCH, 2011, p. 39). Essa característica inacreditável dos Programas implementados nos Estados Unidos torna-se fato também no que vem acontecendo com a Educação no Brasil. Outra característica que une as experiências dos dois países é que se trata de um grande negócio que beneficia os interesses empresariais dos principais conglomerados ligados aos políticos centrais desses países.

No Brasil, o Movimento Todos pela Educação, a versão de reformadores empresariais dos Corporaters Reformers dos Estados Unidos, vem tendo êxito em promover a política educacional de acordo com a perspectiva que defendem. A esse respeito, os estudos de Benittes (2014) apontam que, na atualidade, há uma centralidade da vertente gerencial como referencial das políticas educacionais do país. E que um dos exemplos mais significativos é o Plano de Desenvolvimento da Educação / Plano de Metas Compromisso Todos pela Educação (PDE), que se configura como um modelo centrado na hibridização de concepções de gestão, dentre as quais se destaca a vertente administrativa gerencial. Baseada nos estudos de Camini (2010), a autora afirma que, dentre as diversas ações e programas previstos no Plano de Desenvolvimento da Educação, a metodologia do PDE-Escola é que mais se encontra permeada pela lógica gerencialista, uma vez que esta vincula "[...] metas, investimentos e resultados por meio da provisão de ferramentas de gestão e treinamento" (BENITTES, 2014, p. 43). De acordo com Camini (2010, p. 548), com isso se busca estabelecer "[...] processos de desenvolvimento da escola, 
padrões mínimo de funcionamento, planos de gestão das secretarias, plano de carreira do magistério e mapeamento escolar". Dessa maneira, o PDE-Escola passa a se caracterizar como uma modalidade de intervenção que direciona a gestão da eficiência operacional das escolas para objetivos voltados para a conquista de resultados e o desenvolvimento de produtos.

Por outro lado, Camini (2010) observa que os instrumentos gerenciais previstos no PDE-Escola se propõem a colaborar com a organização da rotina escolar, ao mesmo tempo em que dificultam ou até mesmo impedem as decisões coletivas da comunidade sobre as questões mais pedagógicas, uma vez que a estratégia "democrática" desse programa (e do próprio PDE) prediz uma forma de democracia induzida ou consentida, que encobre sob a forma de descentralização das decisões a ingerência e as metas exógenas de certas instâncias político-administrativas sobre as outras.

A política de parceria do governo Eduardo Campos (2007-2014) se apresentou como diferente do seu antecessor ao anunciar o encerramento da parceria com o ICE, que praticamente coordenou o PROCENTRO. Entretanto a presença do ICE e de outros parceiros na produção das Escolas de Referência mudou de forma, mas não de conteúdo. De acordo com Morais (2013, p. 128-9),

Dentre seus parceiros destacamos os seguintes: a Associação Vida e Natureza (AVINA) fundação de origem suíça, responsável pela formação de Gestores Escolares na Tecnologia Empresarial Sócio-educacional - TESE e em Protagonismo Juvenil, bem como de professores de Ciências Exatas e da Natureza e Laboratoristas; Governo da República Federal da Alemanha, cuja parceria acontece sob a forma de implantação de laboratórios para o ensino da língua alemã e introdução das escolas no Programa PASCH e intercâmbios; Governo dos Estados Unidos, com a implantação do Programa Access to the Future e intercâmbios; Junior Achievement, responsável pela implantação de programas de educação financeira, economia de mercado e empreendedorismo juvenil através dos programas Miniempresas e Torneio de Decisões Empresariais; e Modus Faciendi (MG), a parceria acontece através da implantação de ações formativas e desenvolvimento de instrumentos voltados à ação escolar nos âmbitos do Protagonismo Juvenil, da Educação para Valores, da Cultura da Trabalhabilidade, da Cultura de Paz e da Pedagogia da Presença.

Outra forma de utilização que o PEl engendra é a verificada por Morais (2013) como "presença territorial" a partir do foco na interiorização que o Programa 
persegue através do art. 2ำ, parágrafo III da Lei Complementar n. 125 de 10 de julho de 20085: "[...] difundir o modelo de educação integral no Estado, com foco na interiorização das ações do governo e na adequação da capacitação de mão de obra, conforme vocação econômica da região". De acordo com Morais (2013, p. 130), nesse sentido a esfera de atuação da escola estaria sendo ampliada para corrigir ausências de outros setores do Estado. Sobre isso, de acordo com Algebaile (2009, p. 329),

A realização concreta ou a simulação, por meio da escola, de certas ações que, em tese, deveriam caber a outros setores do Estado, da sociedade, do capital são úteis, especialmente, porque dissimulam as omissões do Estado na oferta ampla e na regulação dessas ações.

De acordo com Morais (2013, p. 130),

A outra forma de utilização é a formação para a empregabilidade e o empreendedorismo, como forma de enfrentar o fato de que não haverá emprego para todos. Assim, a função principal das EREMs é a formação dos jovens para a sociabilidade do capital.

Para Alves (2007), o toyotismo, com sua promessa de "produção enxuta", não garante a efetivação da promessa integradora do mundo do trabalho. Portanto a forma de combater essa questão é através da construção da subjetividade de que o trabalhador deva se formar empreendedor de si mesmo (APPLE, 2015).

De acordo com Algebaile (2009), a escola brasileira vem sendo utilizada para outros fins, que não os educativos, com o custo de um processo de empobrecimento em relação a seus objetivos, e a sua "utilização para responder tópica e seletivamente aos problemas sociais tornou inevitável sua desqualificação para o ensino" (ALGEBAILE, 2009, p. 331). A autora chama esse processo de "robustecimento" da escola, que lhe gera a precarização:

Trata-se de um eixo de expansão que decorre das múltiplas e persistentes tentativas de utilização, concreta ou simbólica, da escola; utilizações que repercutem em sua constituição, tornando-a, sob certos aspectos, mais robusta, ainda que isso represente sua fragilização em aspectos que deveriam ser essenciais. (ALGEBAILE, 2009, p. 148).

\footnotetext{
${ }^{5}$ Que pode ser acessada através do link: http://legis.alepe.pe.gov.br/arquivoTexto.aspx?tiponor $\mathrm{ma}=2 \&$ numero=125\&complemento=0\&ano=2008\&tipo=\&url, acesso em 10 de julho de 2017.
} 
De acordo com Morais (2013),

[...] a mesma concepção está presente no PEI quando este através dos documentos legais afirma que a Educação e a formação oferecidas nas EREMs contribuem para diminuir as desigualdades regionais dentro do Estado de Pernambuco através da qualificação da juventude representando um importante instrumento de modernização e consequente desenvolvimento.

Algebaile (2009, p. 242) chama atenção para o fato de que não é apenas a questão do acesso à escola que garante aos mais pobres uma participação menos marginal na vida, mas a "superação do padrão de acesso desigual" é que representaria algo significativo nesse processo. O PEl, ao contrário disso, representa a consolidação da dualidade da escola criando, em uma mesma Rede de Ensino, percursos formativos para o ensino médio que segmenta e exclui o atendimento dos segmentos mais pobres.

\section{CONCLUSÃO}

As utilizações do Programa de Educação Integral (PEI) no Ensino Médio regular em Pernambuco, considerando as promessas de formação de jovens, de acordo com as análises que fizemos, envolvem a oferta de Ensino Médio em tempo integral nas Escolas de Referência em Ensino Médio (EREMs) e nas Escolas Técnicas Estaduais (ETEs). No entanto envolvem também a existência, na mesma Rede de Ensino, do Ensino Médio regular em tempo parcial e a modalidade Educação de Jovens e Adultos (EJA), além do Normal médio e de projetos de aceleração da aprendizagem.

Na consideração das utilizações da escola através do processo de implementação do PEl, identificamos uma concepção de educação integral como educação interdimensional, que busca formar a juventude de acordo com a perspectiva dos organismos internacionais a qual, no fundo, está de acordo com os interesses do Capital, promovendo uma organização do trabalho pedagógico naquilo que Saviani (2011) chama de neoprodutismo e suas variantes (neotecnicismo, neo-escolanovismo e neoconstrutivismo). Na esteira desse processo, está a relação estreita que se estabelece no Estado com a iniciativa privada, com os chamados reformadores empresariais (RAVITCH, 2011; FREITAS, 2012), através de Parcerias Público-Privadas (PPPs) e através da ênfase na gestão gerencial, nos moldes do 
mercado, com base em mecanismos de responsabilização e com ênfase na formação de jovens empreendedores de si mesmos (APPLE, 2015).

Considerando tais elementos, a ênfase maior tem sido no controle dos elementos subjetivos nesse processo de organização do trabalho da escola, cuja ênfase maior vem sendo no controle do tempo, intensificação e precarização do trabalho docente. Isso, inclusive ao limitar as possibilidades de organização coletiva dos professores para garantia de seus direitos e de possibilidades individuais de continuidade de estudos e de realização de projetos pessoais e de cuidados com a própria saúde.

Tais utilizações repercutem na constituição da escola de ensino médio em Pernambuco, mesmo as que não adotam o PEI diretamente, sobretudo porque estão fundadas na dualidade da oferta escolar que cria, assim como observado por Algebaile (2009), uma escola pobre para os pobres. E mais, como observado por Freitas (2012), cria itinerários formativos desiguais na própria escola pública.

\section{REFERÊNCIAS}

ALGEBAILE, Eveline. Escola Pública e Pobreza no Brasil: a ampliação para menos. Rio de Janeiro: Lamparina, 2009.

ALVES, Giovani. Dimensões da reestruturação produtiva: ensaios de sociologia do trabalho. 2. ed. Londrina: Práxis; Bauru: Canal 6, 2007.

APPLE, Michael W. Produzindo diferença: noliberalismo, neoconservadorismo e a política de reforma educacional. Linhas Críticas, Brasília, DF, n. 46, p. 606-44, set./dez. 2015.

BENITTES, Valéria Andrioni. A política do ensino médio no estado de Pernambuco: um protótipo de gestão da educação em tempo integral. 2014. 118f. Orientador: Jamerson Antonio de Almeida da Silva. Dissertação (Mestrado em Educação Contemporânea) Universidade Federal de Pernambuco, Caruaru, PE, 2014.

CAMINI, Lucia. A política educacional do PDE e do Plano de Metas Compromisso Todos pela Educação. Revista RBPAE, Recife, v. 26, n. 3, p. 535-50, set./dez. 2010.

CASTRO, Maria Helena Guimarães. Avaliação de políticas e programas sociais. Cadernos de Pesquisa, Campinas, n. 12, p. 1-5, 1989.

COSTA, Antonio Carlos Gomes da. Educação - uma perspectiva para o Século XXI. São Paulo: Canção Nova, 2008. 
FREITAS, Luiz Carlos de. Os Reformadores Empresariais da Educação: da desmoralização do magistério à destruição do sistema público de educação. Revista Educação e Sociedade, Campinas, v. 33, n. 119, p. 379-404, abr./jun. 2012.

FREITAS, Luiz Carlos de. Os reformadores empresariais da educação e a disputa pelo controle do processo pedagógico na escola. Educ. Soc., Campinas, v. 35, n. 129, p. 10851114, out-dez, 2014.

LEFEBVRE, Henri. La presencia y La ausência: contribuición a La teoria de las representaciones. México: FCE, 2006.

MAGALHÃES, Marcos. A juventude brasileira ganha uma nova escola de Ensino Médio: Pernambuco cria, experimenta e aprova. São Paulo: Albatroz, Loqui, 2008.

MAUÉS, Olgaíses Cabral. O papel da escola na construção dos saberes e os limites da noção de competências. In: FERREIRA, E. B; OLIVEIRA, D. A. Crise da escola e políticas educativas. Belo Horizonte: Autêntica, 2009.

MORAIS, Edima Verônica de. Utilizações das escolas de referência em Ensino Médio pelo Governo do Estado de Pernambuco: uma análise do Programa de Educação Integral. Orientador: Jamerson Antonio de Almeida da Silva. 2013. 198f. Dissertação (Mestrado em Educação Contemporânea) - Universidade Federal de Pernambuco, Caruaru, PE, 2013.

PERNAMBUCO (estado). Secretaria de Educação. Proposta Curricular para o Ensino Médio Integral. Recife, 2010.

RAVITCH, Diane. Vida e morte do Grande Sistema Escolar Americano - como os testes padronizados e o modelo de mercado ameaçam a Educação. Porto Alegre: Sulina, 2011.

SAVIANI, Dermeval. História das ideias pedagógicas no Brasil. 3. ed. rev. 1 reimpr. Campinas, SP: Autores Associados, 2011.

SILVA, Katharine Ninive Pinto; SILVA, Jamerson Antonio de Almeida da. Política de Avaliação e Programa de Educação Integral no Ensino Médio da Rede Estadual de Pernambuco: os limites da centralidade da avaliação nas políticas educacionais. Práxis Educativa, Ponta Grossa, p. 736-56, v. 11, n. 3, set./dez., 2016. 


\section{Sobre os autores:}

Jamerson Antonio de Almeida da Silva - Doutor em Educação pela Universidade Federal da Bahia (UFBA). Professor do Programa de Pós-Graduação em Educação da Universidade Federal de Pernambuco. E-mail: jamersonufpe@gmail.com, Orcid: http://orcid.org/0000-0002-4198-8049

Katharine Ninive Pinto Silva - Doutora em Educação pela Universidade Federal da Bahia (UFBA). Professora do Programa de Pós-Graduação em Educação da Universidade Federal de Pernambuco. E-mail: katharineninive@gmail.com, Orcid: http://orcid.org/0000-0002-7293-4289

Recebido em fevereiro de 2018 Aprovado em março de 2019 
